\title{
Los VII goyos de la Virgen en las Cantigas de Santa María y la tradición de los gaudia en la poesía medieval latina y vernácula
}

Santiago Disalvo Universidad de la Plata de Buenos Aires

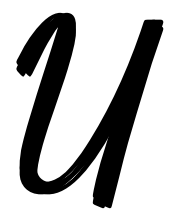

n extenso y antiguo canto en honor a la Virgen María, la saluda doce veces con palabras de gozo: "Chaîre, nýmphe anýmpheute!" ("Alégrate", o bien, "Salve, esposa no desposada"). Es el himno griego Akáthistos, incluido en la liturgia bizantina, en el que el anuncio angélico, que reitera las salutaciones de bienaventuranza (chairetismoî), se dirige a la Virgen con múltiples advocaciones y epítetos que permanecerán en la tradición himnódica. ${ }^{1}$ Pocos siglos más tarde, en el otro extremo de Europa, el anglosajón Cynewulf, en un largo poema épico religioso titulado Crist, invoca a la Virgen llamándola:

Eala wifa wynn geond wuldres prym.

Famne freo-licast ofer ealne foldan sceat

Dass pe afre sund-buend secgan hyrdon.

Arece us pat geryne pat pe of roderum cwom

${ }^{1}$ Atribuido a Romano el Meloda (s. VI), el himno es fechado por los estudios más recientes en la primera mitad del siglo V: "My conclusión is that the terminus ante quem for the hymn's composition is the Council of Chalcedon of 451" (PELTOMAA, 2001, p. 114). 
Hu pu eacnunge afre onfenge

Bearnes purh gebyrde ond pone gebed-scipe

After mon-wisan mod ne cuðes.

(vv. 70-73; GOLLANCZ, 1892, p. 8)

¡Ea, gozo entre las mujeres por sobre el esplendor de la gloria [del cielo],

doncella, la más noble sobre la faz de la tierra

de la que los moradores del mar jamás hayan oído decir!

Muéstranos el misterio que te vino del firmamento, cómo tú el parto has aceptado

mediante el nacimiento de un hijo y aun así la unión según manera humana no conociste.

Wynn es la antigua palabra inglesa que designa gozo o alegría (NORTHCOTE, 1921), y así, "wifa wynn", "gozo de las mujeres", "gozo (o gozosa) entre las mujeres", podría ser una fórmula asimilable a "decus mulierum" y entroncaría, pues, con la himnodia litúrgica incluida en las fiestas marianas de oracionales y antifonarios medievales: Ave decus virginum, Salve decus mulierum. ${ }^{2}$ Podemos ver que, desde los primeros siglos de la Edad Media, la Virgen es asociada y aun identificada con el gozo mismo. Así acontecerá también en escritos de poetas medievales posteriores, como Axi con cel c'anan erra la via del catalán Cerverí de Girona (siglo XIII) o, ya en lengua castellana, el poema del Marqués de Santillana (siglo XV), que será mencionado más adelante. En el canto de Cerverí, el trovador insta a los hombres a buscar la luz

${ }^{2}$ No debe desestimarse la posibilidad de que grandes himnógrafos de la temprana Edad Media, como San Beda, hayan podido influir en esta poesía vernácula coterránea y posterior en poco tiempo. "Et tu beata prae omnibus, / Virgo Maria, feminis, / Dei Genitrix inclyta, / Nostris faveto laudibus. // [...] // Sublimis inter splendida / Apostolorum sidera, / Flamma, sacrique Spiritus / Impleta laudes concinis" (BEDA EL VENERABLE. HYMNUS XI. In Natali sanctae Dei Genitricis, col. 631B). 
de esta alba que es la Virgen, "pues nadie puede llegar al día sin alba, ni discernir el sol" que es Dios, contraponiéndose de esta manera a la bien conocida tradición trovadoresca de las albas, en la que los amantes aborrecen la luz del amanecer:

Gaugs es elutz, stella que 1 mon guia,
e anc no fo domna d'aytal natura
c'on mays sofre de preyadors, melura.

(vv. 36-38; ALVAR, 1999, p. 224)

[Gozo es y luz, estrella que al mundo guía,

y nunca hubo señora de tal naturaleza,

que donde más sufre de rogadores, mejora.]

Margherita Morreale (1984), al estudiar los Gozos incluido en el Libro de buen amor de Juan Ruiz, destaca, a partir de su origen bíblico, la concepción cristiana de gozo que recorre la cultura desde el Antiguo Testamento, pasando por el Nuevo y los evangelios apócrifos, hasta la himnodia latina de donde se trasvasa a la poesía vernácula. El gozo humano y sobrenatural de María, y la invocación de su persona como gozosa, han tenido, pues, una larga historia poética desde el Evangelio de Lucas (en el que se hallan la salutación del arcángel y de Santa Isabel, además de los cánticos evangélicos), pasando luego también a la literatura hagiográfica y miracular en las visiones de santos y devotos sobre los gozos de María, y a diversos tratados teológicos y mariológicos, tanto medievales como modernos. ${ }^{3}$

${ }^{3}$ Así, pues, el himnógrafo y teólogo británico Frederick William Faber (1814 -1863) relata varios casos de tales visiones en su obra All for Jesus, or The Easy Ways of Divine Love (1853). Por ejemplo, Santo Tomás de Canterbury, que acostumbraba recitar siete avemarías al día en honor de los gozos de la Virgen, había recibido de ella misma la instrucción de celebrar sus gozos celestiales (y no sólo terrenales), con promesas de grandes recompensas. Y sobre esto el santo habría escrito la secuencia Gaude flore virginali, cantada 
Desde el siglo XI ya puede encontrarse conformado un subgénero lírico particular, de asunto mariano, los gaudia o gozos de la Virgen. Su origen, poco esclarecido aún, suele indicarse en los cánones del rito bizantino, o bien en las antífonas y los oficios rimados de la liturgia romana del siglo X. Así, por ejemplo, existen antiguas antífonas que invocan el gozo de la Virgen, como "Gaude Maria virgo cunctas haereses sola interemisti [universo mundo] [sancta Dei genitrix]" (HESBERT, 1963-79; Silos, ms. S). ${ }^{4}$

Lo cierto es que, de todas maneras, la costumbre de cantar los gozos de la Virgen no sólo alimentó la himnodia latina y la lírica vernácula letrada, sino que, con diferentes formulaciones, muchas veces en forma de poemas con estribillo y repeticiones paralelísticas de diverso tipo, arraigó muy profundamente en la cultura popular occidental, en la poesía hispánica y, con especial riqueza, en la tradición de los goigs o gojos valencianos, catalanes y aragoneses. "Y en este punto, por fuerza, cabe hacer

después en algunas iglesias (FABER, 1866, p. 249-252). Según este autor, otras revelaciones similares acontecieron a Santa Catalina de Bolonia, al Beato Ranulfo, al Beato Premonstratense José Herman y a cierto monje que, como relata un texto de San Pedro Damián, al pasar ante el altar de la Virgen, la saludaba con la antífona latina del Gaude, la misma que traen las fuentes de milagros universales como Pez o Thott 128, retomada en la obra de Gonzalo de Berceo. ${ }^{4}$ Según otras versiones: "Gaude Maria virgo cunctas haereses sola interemisti quae Gabrielis archangeli dictis credidisti dum virgo deum et hominem genuisti et post partum virgo inviolata permansisti alleluia". 5 "Aunque existen gozos en toda España es en el ámbito aragonés, catalán y valenciano los territorios en los que se encuentra un mayor número. Los gozos son también conocidos en Cerdeña como 'goccius' o 'gosos' por la influencia durante siglos de Cataluña en la isla" (SÁNCHEZ UNGRÍA, 2008, p. 257). Atesorados y estudiados, por ejemplo, por los 
una pequeña anotación, pues no solo en la catalana, sino también en la literatura sarda los goigs o gòsos se convierten en un género específico", puntualiza Marina Romero Frías

Gogistes Valencians (Asociación Cultural Via Vicentius, 2010), los goigs o gojos son composiciones poéticas populares que se cantan en honor de la Virgen, Cristo o los santos, en celebraciones litúrgicas, procesiones, bendiciones de imágenes, en acción de gracias por beneficios recibidos o bien como súplicas para implorar protección contra eventuales males. $\mathrm{Su}$ vida es tanto oral como escrita, ya que en muchos casos se imprimen en pliegos o documentos ricamente elaborados. A la tradición de estos gozos marianos atañe la creación moderna de poemas en alabanza a Santa María con alguna advocación local, como en el caso de los Gozos de la Virgen de las Cuevas, patrona de Caminreal en la Comarca de Jiloca, provincia de Teruel (LÁZARO POLO, 1989), supuestamente recogidos o reelaborados por el sacerdote D. Augusto Godoy Beltrán en 1932. María José Sánchez Ungría (2008, p. 257) describe los rasgos fundamentales de tales manifestaciones populares aragonesas: "Estas composiciones suelen presentar características comunes a otras piezas de folklore musical, esto es, autoría anónima y contenido textual de carácter colectivo, aunque se conservan varios gozos de compositores importantes en las catedrales aragonesas obras de Simon Benedi (Gozos a Nuestra Señora del Carmen), Domingo Cuéllar (Gozos a Nuestra Señora de la Aurora y Gozos a Santo Tomás de Aquino), Nicolás Ledesma (Gozos a San José) y Celestino Vila (Gozos a la Virgen de las Mercedes, Gozos a Nuestra Señora del Carmen, Gozos a San Luis Gonzaga, Gozos a Santa Teresa de Jesús...) entre otros compositores en la catedral de Huesca". La autora da razón, asimismo, de la frecuencia de los gozos marianos en el Aragón moderno: "Las apariciones de imágenes de la Virgen son muy frecuentes en toda la geografía aragonesa y, en consecuencia, se conservan numerosos mariológicos (Gozos de Nuestra Señora de la Guardia en Rocafort, Gozos de Nuestra Señora de la Mora en Peralta de la Sal, Gozos de Nuestra Señora de la Ganza en Calasanz, Gozos de la Virgen de la Vilavella en Baldellou y Gozos a la Virgen de Vilet en Gabasa). El carácter rogativo aparece con claridad y de forma muy amplia, solicitando 'amparo y benignitat' (Goigs en honor de Santa Ana en Pinyana) ante 
(2006), ${ }^{6}$ afirmación que podría extenderse, si bien se mira, hasta las canciones del folklore angloamericano. ${ }^{7}$

Uno de los himnos latinos más célebres y difundidos en Europa occidental parece estar en la base de muchas otras versiones de gaudia marianos construidas después:
Gavde virgo, mater Christi,
[3] Gabriele nuncio.
que per aurem concepisti
Gaude quia Deo plena, peperisti sine pena
[6] cum pudoris lilio.
Gaude quia tui nati, quem dolebas mortem pati,
[9] fulget resurrectio.

'cualquiera mal o dolencia' (Gozos de Nuestra Señora de la Mora en Peralta de la Sal)..." (SÁNCHEZ UNGRÍA, 2008, p. 260).

${ }^{6}$ La autora retoma las palabras de Giampaolo Mela (2005), especialmente sugestivas para el presente trabajo, ya que enlazan esta tradición en la modernidad con la música de las Cantigas de Santa María: "Il gaudium, riferito alle gioie della Vergine, giunse nella monodia devozionale sarda, tramite appunto la mediazione iberica (secc. XIV-XVIII). Infatti il vocabolo gòsos / gòtzos / cózzos, diffuso nella Sardegna Centrale e Settentrionale, deriva dal castigliano gozos, mentre la variante gòggius / góccius / cóccius / còggius, presente nel Sud dell'isola, trae le sue radici dal catalano goigs, in Gallura si ha invece la voce gósi. La melodia più diffusa dei gósos sardi richiama l'estribillo della cantiga di Santa Maria $\mathrm{n}^{\circ} 140, A$ Santa Maria dadas serian loores onrradas (sebbene non sussistano certezze di filiazione diretta)" (citado en ROMERO FRÍAS, 2006).

${ }^{7}$ La canción "The Seven Joys of Mary", popular en el folklore canadiense (Newfoundland), es cantada hoy en día por el grupo Great Big Sea y, en una versión musical diferente ("The Seven Rejoices of Mary"), por la solista y compositora irlandesa Loreena McKennitt. 
Gaude Christo ascendente, quod in celum, te vidente,

[12] motu fertur proprio.

Gaude quod post ipsum scandis, et est honor tibi grandis

[15] in celi palatio.

Vbi fructus ventris tui per te detur nobis frui:

[18] in perenni gaudio. (citado en WEBER, 1969, p. 155)

El himno, como puede verse, celebra cinco gaudia o gozos de la Virgen (Anunciación, Natividad, Resurrección, Ascención, Asunción), con la petición final de participar del gozo eterno. La gran compilación de Clemens Blume y Guido Dreves, Analecta Hymnica Medii Ævi (AHMAE), consigna más de doscientas piezas bajo el rótulo Gaudia B.M.V., de extensión muy variable, en breviarios e himnarios entre los siglos XI y XVII, desde glosas y largos oficios rimados para todas las horas canónicas hasta secuencias e himnos más breves. ${ }^{8}$

La devoción de los cinco gozos de la Virgen ya era popular en Inglaterra para la época de la conquista normanda. Una de las formas poéticas más antiguas de esta devoción parece haber sido

${ }^{8}$ En un primer acercamiento, he detectado en los volúmenes de AHM $E$ un número aproximado de 212 piezas de Gaudia en honor a la Virgen. Destaco sólo algunos volúmenes y sus piezas: Vol. 1: pieza 111 // Vol. 3: piezas 34 y 178 // Vol. 8 (liturgische Prosen de las páginas 57 a 58) // Vol. 9: pieza 54 // Vol. 15: piezas 60 a 74 (casi todos sobre la base del Gaude Virgo, Mater Christi), 93, 95 a 97 // Vol. 24: piezas 156, 159, 160, 162 a 167, 170, 172 // Vol. 31: piezas 170 a 194 (p. 175-203) // Vol. 39: piezas 55 // Vol. 40: pieza 83 // Vol. 42: piezas 53, 81, 82, 83 // Vol. 46: piezas 132, 136 // Vol. 54: pieza 332. Según parece, el número de gozos celebrado en los poemas es, en orden decreciente: VII, V, XII, IX, X, XV, XIV. 
el mencionado himno Gaude Virgo, Mater Christi, incluido en las Horae Eboracenses (oficio mariano de las horas según el uso de York), el cual pudo haber inspirado una veintena de poemas sobre gozos marianos en inglés medio, entre los cuales se destaca Glade us Maiden, moder milde (WEBER, 1969, p. 152-153). Una de las muestras de la gran difusión de este subgénero, al menos en el ámbito literario, es su presencia en la narrativa. Así, por ejemplo, en el célebre romance artúrico del siglo XIV, Sir Gawain and the Green Knight, los cinco gozos de la Virgen -junto con los cinco sentidos, los dedos de la mano y las cinco llagas de Cristo crucificado- son mentados al describir la figura del Pentangle ("pentángulo", o estrella de cinco puntas de Salomón) en las armas del guerrero: "That all his forsnes he fong at the fyoe joyes / That the hende heven-quene had of hir childe" ["que toda su fortaleza recibía de los cinco gozos / que la gentil Reina del Cielo tuvo de su hijo"] (vv. 645-646; BURROW, 1972, p. 34). En la poesía francesa, cinco son también los gozos con los que Gautier de Coinci (ss. XII-XIII) cierra su gran obra mariana, los Miracles de Nostre Dame, "Ce sont les Cinc Joies Nostre Dame" (II Prière 39; KOENIG, 1970, p. 589-590), pidiendo ser escuchado en su ardiente súplica final.

El subgénero será retomado una y otra vez en la Península Ibérica durante la Baja Edad Media. Así, pues, en la última década del siglo XX, Ángel Gómez Moreno daba a conocer unos gozos marianos compuestos en castellano hacia el año 1300, en cuaderna vía (GÓMEZ MORENO, 1990; 1991). ${ }^{9}$ En el siglo XIV hispánico,

${ }^{9}$ El estrecho vínculo de las formas vernáculas con la himnodia y la poesía latina litúrgica en general, ha sido señalado por los estudiosos de la cuaderna vía: "La vinculación del género de las prosas y los tropos con los himnos lleva consigo la relación con otras formas poéticas, como son las laudes, los gozos, o los milagros marianos, cuyas formas y temática aparecen manifestadas en nuestra literatura en cuaderna vía, así como en sus congéneres romances, como la francesa o la italiana" (GONZÁLEZ-BLANCO GARCÍA, 2008, p. 205). 
dos obras de peso incluyen gozos marianos: el Llibre Vermell de Montserrat, que contiene cantos en latín y en lengua catalana, y las cantigas marianas insertas en el Libro de buen amor de Juan Ruiz, Arcipreste de Hita. Los siete gozos dedicados a la Madona Bruna de Montserrat son acaso el ejemplo más claro de la mezcla de la tradición letrada latina con elementos poéticos y musicales de la tradición vernácula: "Los set gotxs recomptarem et devotament xantant / humilment saludarem la dolça verge Maria. / Ave Maria gracia plena Dominus tecum Virgo serena" (GÓMEZMUNTANÉ, 1990). Su título, "Ballada dels goytxs de Nostre Dona en vulgar cathallan a ball redon", indica que se trataba de una obra de tradición popular o, al menos, de estilo popularizante, usada probablemente por los peregrinos y devotos para las danzas en ronda ("ball redon") en el santuario.

En lengua castellana, la obra del Arcipreste de Hita incluye los siete gaudia presentes en la tradición en forma de cuatro cantigas de variados metros líricos, tanto al inicio como al final del libro: "O María, / luz del día" (estrofas 20-32); "Virgen, del Çielo reina" (estrofas 33-43); "Madre de Dios glorïosa" (estrofas 1635-1641); "Todos bendigamos / a la Virgen Santa" (estrofas 1642-1648). Estos gozos han sido estudiados exhaustivamente, en sus aspectos codicológicos, métricos, morfosintácticos y léxicos, por la erudita italiana Margherita Morreale (1983; 1984), quien destaca que, si bien pueden adscribirse a lo popular, los poemas pertenecen claramente al ámbito de la cultura letrada de la que participaba Juan Ruiz. Así, por ejemplo, la estrofa zejelesca de "O María, /luz del día" presenta semejanzas con el himno Ave, Virgo, Mater Christi (MORREALE, 1983, p. 233), lo cual, entre muchos otros rasgos analizados, muestra que en estos "gozos" convergen subgéneros poéticos de raíz monástica, aunque difundidos en el ámbito popular (MORREALE, 1984).

En el siglo XV, los Gozos de Nuestra Señora, de Don Íñigo López de Mendoza, Marqués de Santillana, serán elaborados como una extensa glosa de alguna versión del himno Gaude Virgo 
Mater Christ $^{10} \mathrm{y}$, asimismo, de otras antífonas y oraciones marianas cuyos versos en latín son citados a lo largo del poema castellano:

I

Gózate, gozosa madre, gozo de la humanidad, templo de la Trinidad elegido por Dios Padre. Virgen, que por el oýdo concepisti, gaude, Virgo, Mater Xhristi, en nuestro gozo infinito.

II

Gózate, luz reverida, segund el Evangelista, por la madre del Babtista, anunçiando la venida de nuestro gozo, Señora, que traýas, vaso de nuestro Mexías gózate, pulcra e decora.

III

Gózate, pues que pariste

Dios y homne por misterio, nuestro bien e refrigerio.

Inviolata permansiste, sin ningund dolor nin pena;

10 "Los versos de que se parte, como en el resto de las estrofas que usan frases latinas, son conocidos poemas religiosos; en este caso, el que comienza Gaude, Virgo, Mater Christi / quae per aurem concepisti, / Gabrielle nuncio" (GÓMEZ MORENO y KERKHOF, 1988, p. 373, nota a la estrofa I). En la estrofa II, la fuente latina es una antífona del Officium Beatae Mariae Virginis, "Pulchra es et decora filia Hierusalem", sintagma que aparece también en las letanías a la Virgen, mientras que la estrofa III parece fundarse sobre la antífona citada en la nota 4 del presente trabajo. 


\section{pues, gozosa,}

gózate, cándida rosa,

Señora de graçia plena.

(vv. 1-24; GÓMEZ MORENO y KERKHOF, 1988, p. 373-374)

En la larga cadena de gozos engarzados, el Marqués de Santillana enumera no ya cinco o siete, sino doce gozos, a saber: la Anunciación, la Visitación a Isabel, la Natividad, la Epifanía, la Presentación en el templo, la aparición del arcángel Gabriel en la huida a Egipto, el hallazgo del niño Jesús en el templo, el primer milagro en las Bodas de Caná, la Resurrección, la Ascensión, el descenso del Espíritu Santo (Pentecostés) y la Asunción de la Virgen.

La alternancia preponderante entre cinco y siete gozos, además del número de doce (suma de los anteriores) y otros menos frecuentes (diez, catorce, quince), ya se advierte en la himnodia litúrgica. El número cinco ha sido asimilado a María, entre otras razones, por las letras de su nombre, el cual formaba parte de prácticas de devoción, junto con otras formas de oraciones encadenadas a Dios o a la Virgen, muy anteriores a la aparición del rosario. En cuanto al número siete, la celebración de los Gozos de María parece haber sido influida por la memoria de los Siete Dolores, fomentada en gran medida por los franciscanos, los dominicos y, sobre todo, los servitas en el siglo XIII. Cabe recordar que la forma actual del rosario, que incluye los "misterios gozosos", de origen dominico, fue finalmente instituida en el siglo XVI, aunque se sostiene, al menos por ciertas tradiciones, que podría datar del siglo XIII. Las quince decenas tradicionales del rosario, divididas en tres misterios de cinco decenas cada uno (misterios gozosos, dolorosos, gloriosos), fueron fijadas con la aprobación pontificia de Pío V en 1569, quien también instituyó su fiesta en 1573, en acción de gracias por la victoria de los cristianos en la batalla de Lepanto. Los orígenes de esta forma del rosario se remontan al 
año 1483 y a la Orden de los Predicadores a quienes se debe la estructura de las quince decenas correspondientes a los quince misterios. Se tiene noticia de otras formas de rosario o de oraciones encadenadas (también con sartas de cuentas, para facilitar la exactitud del recuento), algunas anteriores en varios siglos a la existencia de franciscanos y dominicos. El número de quince decenas (150) proviene de la costumbre monástica de recitar los 150 salmos del salterio en una semana que, trasladada a los usos laicos, adoptó la forma más sencilla de 150 padrenuestros u oraciones a la Virgen (salutaciones angélicas). La corona franciscana, o rosario seráfico, que quedó fijada en el primer cuarto del siglo XV, consta de siete decenas dedicadas a la memoria de los siete gozos de la Virgen (Anunciación, Visitación, Natividad, Epifanía, hallazgo de Jesús en el templo, Resurrección, Asunción-Coronación de la Virgen). La leyenda dice que un novicio franciscano, acostumbrado en su juventud a ofrendar guirnaldas de flores a la estatua de María, salió de la orden al no poder continuar con su práctica devota. En una aparición, Santa María impidió que abandonara a sus hermanos, indicándole que, a cambio de las ofrendas de flores entrelazadas, recitara un rosario con siete decenas en honor de sus siete gozos, usanza que se generalizó pronto entre todos los frailes (DONOVAN, 1908). Este mensaje de la Virgen recuerda mucho el que contienen varios milagros recogidos en las Cantigas de Santa María, según se verá más adelante.

$$
* * *
$$

Si bien la obra de Gautier de Coinci pudo haber tenido su reverberación en las más de cuatrocientas Cantigas de Santa María del rey Alfonso $X$, la pieza correspondiente a los gozos de la Virgen, que es la cantiga 1, sigue la tradición de los siete gozos (en lugar de cinco): 
A primeira cantiga de loor de SANTA Maria EMENTANDO OS VII GOYOS QUE OUVE DE SEU FILLO

Des oge mais quer' eu trobar pola Sennor onrrada, en que Deus quis carne fillar bẽeyta e sagrada, por nos dar gran soldada no seu reyno e nos erdar por seus de sa masnada de vida perlongada, sen avermos pois a passer per mort' outra vegada.

E demais quero-l1' enmentar como chegou canssada a Beleem e foy pousar no portal da entrada, u paryu sen tardada Jesu-Crist', e foy-o deytar, como moller menguada, u deytan a cevada, no presev', e apousentar ontre bestias d'arada.

E non ar quero obridar com' angeos cantada loor a Deus foron cantar e "paz en terra dada"; nen como a contrada aos tres Reis en Ultramar ouv' a strela mostrada, por que sen demorada vẽeron sa offerta dar estranna e preçada.
E poren quero começar como foy saudada de Gabriel, u lle chamar foy: "Benaventurada Virgen, de Deus amada: do que o mund' á de salvar ficas ora prennada; e demais ta cunnada Elisabeth, que foi dultar, é end' envergonnada".

E ar quero-vos demostrar gran lediç' aficada que ouv' ela, u vyu alçar a nuv' enlumẽada seu Fill'; e poys alçada foi, viron angeos andar ontr' a gent' assũada, muy desaconsellada, dizend': "Assi verrá juygar, est' é cousa provada".

Nen quero de dizer leixar de como foy chegada a graça que Deus enviar lle quis, atan grãada, que por el esforçada foy a companna que juntar fez Deus, e enssinada, de Spirit' avondada, por que souberon preegar logo sen alongada. 
Outra razon quero contra que $1 l^{\prime}$ ouve pois contada a Madalena: com' estar vyu a pedr' entornada do sepulcr' e guardada do angeo, que lle falar foy e disse: "Coytada moller, sey confortada, ca Jesu, que vẽes buscar, resurgiu madurgada".
E, par Deus, non é de calar como foy corõada, quando seu Fillo a levar quis, des que foy passada deste mund' e juntada con el no ceo, par a par, e Reỹa chamada, Filla, Madr' e Criada; e poren nos dev' ajudar, ca $x^{\prime}$ é noss' avogada.

(METTMANN, 1986, p. 56-58)

Semejante a los gozos marianos que escribirá el Arcipreste de Hita un siglo más tarde, la cantiga celebra, como puede apreciarse, la Anunciación, la Natividad, la Epifanía, la Resurrección, la Ascensión, Pentecostés y la Asunción. Este número se reflejará en la cantiga 50 del ms. To (403 ed. Mettmann), dedicada a los Siete Dolores de la Virgen y que se adscribe a otra larga tradición litúrgico-poética del planctus mariano y los himnos de Septem Doloribus (cfr. DISALVO, 2012).

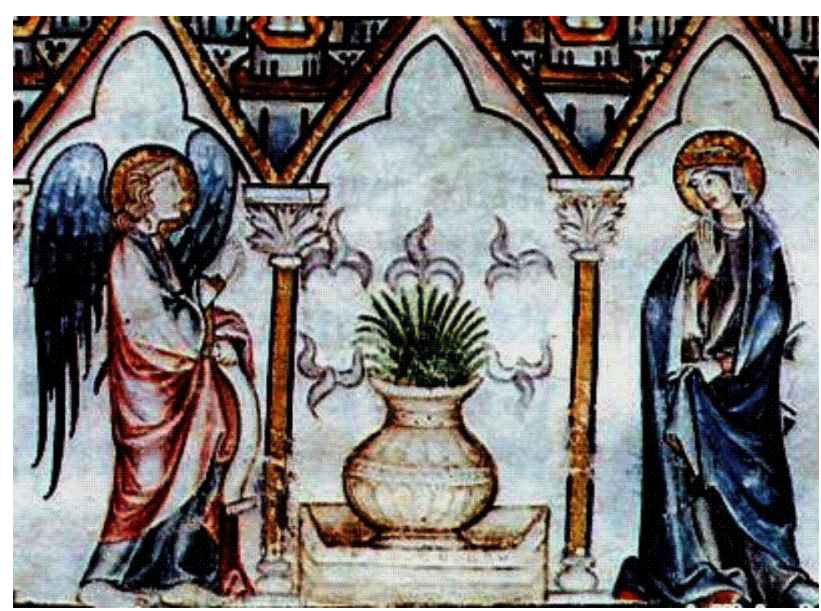

Cantiga 1: gozo de la Anunciación 
Aunque Mettmann (1986, p. 56) señale, como posibles fuentes o cognados de la cantiga 1, los poemas de los oficios rimados recogidos en el volumen 24 de $A H M Æ$ (BLUME, 1896, p. 154-175), no parece haber una razón evidente para ligar la cantiga a este grupo particular de gaudia y no a los más de doscientos poemas restantes que se recogen en los volúmenes de esta gran colección himnódica. La particularidad de esta pieza, además de tratarse de una cantiga de meestria en coblas unissonans (a9b7a9b7b7a9b7b7a9b7) -sin estribillo y correspondiente a una forma de la cançó trovadoresca-, es que ha sido elegida por Alfonso X como una de las cantigas iniciales y la primera cantiga de loor del cancionero, al tiempo que uno de los poemas fundamentales en los que el yo lírico se presenta como trobador de la Virgen. Se manifiesta aquílo que Joseph Snow ha denominado la "palinodia" del rey trovador (SNOW, 1979, p. 308), a saber: el abandono de la actividad trovadoresca profana (las "outras donas" y los "outros amores" mencionados en la cantiga 10) para dedicarse con exclusividad a la santa "Sennor onrrada". Habida cuenta de la declaración prologal del yo lírico/autor (Prólogo B), la cantiga 1 se hace eco de ese preciso momento de inflexión en que el trovador deviene mariano: "quero seer oy mais seu trobador" (Pr. B, v. 19), "Des oge mais quer' eu trobar / pola Sennor onrrada" (cantiga 1, vv. 3-4). Ese yo se transforma en un nosotros al final de la cantiga, con el fin de introducir uno de los tituli más célebres de la Virgen y profusamente empleado en la himnodia litúrgica, que resume en sí uno de los principales objetivos por los que Alfonso X llevó a cabo la magna empresa estética de las Cantigas de Santa María: la Virgen es "noss'avogada", la mediadora que ha de interceder por quienes se ponen a su servicio. ${ }^{11}$ Es de destacar también el léxico

${ }^{11}$ Compárese, en este sentido, con la última estrofa de los ya citados Gozos de Juan Ruiz, "Madre de Dios glorïosa" (perteneciente al conjunto de las piezas líricas finales del Libro de buen amor): "Pídote merced, Gloriosa: / sienpre, toda vegada, / que me seas pïadosa, / 
feudal utilizado para referirse a la recompensa final de la salvación ("gran soldada") que obtendrá la Señora para los suyos, "herencia" prometida a los que son de su masnada, en la cual se incluye el rey Alfonso mismo. ${ }^{12}$ Por otro lado, la consideración de esta cantiga inicial dedicada a los VII goyos no puede dejar de tener en cuenta todo lo que acerca de los gaudia mencionan los milagros marianos, relatados en las mismas cantigas narrativas con las que prosigue la colección, y es en esto en lo que nos detendremos a continuación.

Aunque han sido vertidos eminentemente a la lírica, los gozos hacen su entrada también en la narrativa miracular mariana, en el discurso de los protagonistas de ciertos relatos de milagros "universales", tanto en las primeras colecciones latinas como en las obras marianas posteriores en lengua vernácula (las de Gautier de Coinci, Alfonso X y Gonzalo de Berceo, entre las cuales las dos primeras contienen también Gozos de la Virgen como poesía lírica).

Una vertiente del milagro, la que se halla en las colecciones en lengua latina del códice Pez y del ms. Thott 128 y en los

alegre e pagada; / quando a judgar, / jüizio dar / Jhesú vinier, quierme ayudar / e ser mi abogada" (estrofa 1641; BLECUA, p. 427).

${ }_{12}$ Adviértase que la palabra masnada o mesnada no remite meramente a los súbditos, sino a todos los que están ligados de forma estrecha, militar, política y socialmente, a un señor, aun perteneciendo a estratos sociales diversos: "Los hombres caracterizados por el servicio debido a un mismo señor castellano forman su familia, mesnada o masnada, al margen de que algunos sean miembros de una sola mesnada mientras que otros participan de varias al mismo tiempo. Así, en esta formación social de la mesnada señorial, fundamentalmente centrada en el castillo, se produce la fusión sociológica entre antiguos alodiales y antiguos nobiles, reunidos por el servicio debido al señor (no limitado al simple vínculo feudo-vasallático)" (MORSEL, 2008, p. 147). 
Milagros de Berceo, muestra cómo la Virgen premia a su monje devoto, anunciándole su inminente participación en los gozos del Paraíso. Justamente, el monje la había servido cantando en su alabanza los cinco gaudia en una antífona:

hanc antiphonam in eius laudem mente devota sepe decantabat: "Gaude, Dei genitrix virgo Maria, gaude, que gaudium ab angelo suscepisti, gaude, que genuisti eterni luminis claritatem, gaude, Mater, gaude, sancta Dei Genitrix Virgo, tu sola innupta Mater, te laudat omnis factura Genitricem lucis. Sis pro nobis, quesumus, perpetua interventrix." (CARRERA DE LA RED, 2000, p. 178)

Estos son traducidos por Berceo como los cinco "motes de alegría":

"Gozo ayas, María, que el ángel credist, gozo ayas, María, que virgo conçebist; gozo ayas, María, que a Christo parist, la ley vieja çerresti e la nueva abrist."

(GERLI, 2003, c.119)

La fuente latina establece, consecuentemente, un paralelismo entre los cinco gozos y las cinco llagas de Cristo en la Cruz, provocadas por los pecados que los hombres perpetran con sus cinco sentidos. ${ }^{13}$ El milagro 4 de Berceo reproducirá, en todo, estos elementos de la redacción latina (que es la de Thott 4 y Pez 4), señalando asimismo la rareza del premio, es decir, la muerte del monje y el inmediato acceso de su alma al Paraíso.

${ }^{13}$ Acaso pueda verse en el ya citado milagro de Vicente de Beauvais (XXI. 116.2), una alusión a los cinco sentidos (y, por extensión, a sus pecados), en el hecho de que las rosas florecen de los ojos, la boca y las orejas del monje, sentidos ahora ya del todo redimidos y consagrados exclusivamente a la beatitud y la alabanza mariana. 
Otra vertiente del mismo milagro es la que narra la pieza 56 de las Cantigas de Santa María (según el ms. E; "ESTAÉ COMO SANTA MARIA FEZ NACER AS CINCO ROSAS NA BOCA DO MONGE DEPOS SSA MORTE, POLOS CINCO SALMOS QUE DIZIA A ONRRA DAS CINCO LETERAS QUE Á NO SEU NOME"; METTMANN, 1986, p. 193). Se trata de una devoción ligada a la difusión del rezo del Officium Paroum de la Virgen. La versión correspondiente, inserta en el Speculum historiale de Vicente de Beauvais (XXI. 116.2), explica con precisión los orígenes de tal devoción. Cierto monje llamado Joscius, del monasterio de San Bertino, habría adoptado la devoción del rezo de los cinco salmos en honor al nombre de María, después de haber oído el relato del Arzobispo de Canterbury (que, a su vez, él había oído en Benevento de boca de un hombre religioso), acerca de esta costumbre entre los cristianos de Jerusalén. Joscius, habiendo frecuentado tal práctica, fue hallado muerto en su celda con cinco rosas que florecían de su boca, sus ojos y sus orejas. La flor que salía de su boca llevaba escrito el nombre de María. El relato termina con la inspección y corroboración del milagro en el monasterio por parte de ciertos obispos, entre los cuales se encontraba un célebre abad cisterciense. La nueva devoción jerosolimitana consistía en una suerte de "rosario" a base de salmos y cánticos (Luc.1,46 "Magnificat"; Ps.119; Ps.118; Ps.125; Ps.122):

quod in illa terra quinque psalmos, incipientes a singulis literis nominis beatae Mariae in honorem \& memoriam ipsius frequentare multi consueuerant: scilicet, Magnificat, Ad dominum cum tribularer, Retribue, In conuertendo, Ad te leuaui: singulis Aue Maria praemittentes. (VICENTE DE BEAUVAIS, 1624, p. 264)

En la versión de Gautier de Coinci, que también transmite los mismos salmos, aunque no el nombre del protagonista, se describe el deseo ardiente de éste de servir a la Madre de Dios, con una plegaria con la que pudiera hacer "apropiada memoria" de ella: 
Mais mout estoit ses cuers destróis

Et destorbez de grant manière

Quant ne savoit propre proiere

Dont il fesiste propre mimoire

De la prope dame de gloire.

Il en fu tant en grant perpens

$C^{\prime}$ une en trova selonc son sens:

Cinc saumes prist, ses maria

As cinc lettres de MARIA.

Tant eut de sens qu'il seut bien metre

Une saume a chascune lettre;

$\mathrm{N}^{\prime}$ i quist autre phylosophye

(I Mir 23, vv. 14-25; KOENIG, 1961, p. 224-225)

$\mathrm{Y}$, finalmente, en la cantiga se narra:

Dos salmos foi escoller

cinque por esta razon

e de ssũu os põer

por cinque letras que son

en Maria, por prender

dela pois tal galardon,

per que podesse veer

o seu Fillo piadoso.

Quen catar e revolver

estes salmos, achará

Magnificat y jazer,

e Ad Dominum y á,

e cabo del In conver-

tendo e Ad te está,

e pois Retribue ser-

vo tuo muit' omildoso.

(cantiga 56, vv. 26-42; METTMANN, 1986, p. 193-194) 
La cantiga resalta, pues, la condición de "clérigo simple" o "ignorante" del protagonista, similar al de la cantiga 32 ("ESTA É COMO SANTA MARIA AMẼAÇOU O BISPO QUE DESCOMUNGOU O CRERIGO QUE NON SABIA DIZER OUTRA MISSA SENON A SUA"), pero deseoso de acrecentar su alabanza a la Virgen:

$$
\begin{aligned}
& \text { Este sabia leer } \\
& \text { pouco, com' oý contar, } \\
& \text { mas sabia ben querer } \\
& \text { a Virgen que non á par; } \\
& \text { e poren foi compõer }{ }^{14} \\
& \text { cinque salmos e juntar, } \\
& \text { por en ssa loor crecer, } \\
& \text { de que era desejoso. }
\end{aligned}
$$

(cantiga 56, vv. 17-24; METTMANN, 1986, p. 193)

En sus dos vertientes, este milagro testimonia, una vez más, los orígenes monásticos de ciertas devociones marianas. No es sólo la tradición de los gozos la que está profundamente enraizada en la poesía latina y vernácula del siglo XIII, sino también la costumbre de la veneración del nombre de María (a través de salmos, por ejemplo). En las Cantigas de Santa María se encuentran ejemplos tanto de una como de otra tradición, como se aprecia en las cantigas 1 y 6, y en la 70 y el Prologo das Festas de Santa Maria (410 ed. Mettmann), respectivamente. ${ }^{15}$ Estas

\footnotetext{
${ }^{14}$ El verbo compõer tiene aquí el sentido de "compilar" o "reunir en una colección", más que el de "crear".

${ }^{15}$ Recuérdese que Gautier de Coinci también incluye poesías líricas análogas en su obra mariana: en el Prólogo (I Pr 1): “C'est mers c'onques nus n'espuisa. / Veez son nom: M et puis A, / R et puis I, puis A, et puis / Mers troverés, ne mie puis" (vv. 45-48); y también en los Salus Nostre Dame (II Sal 35), vv. 69-88 (KOENIG, 1966, p. 3-4 y KOENIG, 1970, p. 548-549, respectivamente).
} 
últimas las se conectan con la cantiga 56 por celebrar las cinco letras del nombre de María:

Eno nome de Maria

çinque letras, no-mais, y á.

$M$ mostra MADR' E MAYOR

e mais MANSA e mui MELLOR

de quant' al fez Nostro Sennor

nen que fazer poderia.

Eno nome de Maria...

$A$ demostra AVogada, APOSTA E AORADA,

e AMIGA e AMADA

da mui santa compannia.

(cantiga 70, vv. 3-13; ; METTMANN, 1986, p. 235)

Prologo das Cantigas das Cinco Festas de Santa Maria

Quem Santa Maria servir, non pode no seu bem falir.

...

Santa Egreja ordin[n]ou

çinque festas porque achou

çinque letras no nome sou, como vos quero depa[r]tir.

(Pr. Festas, ms. To 50; vv. 2-3; 14-17;

cantiga 410 ed. METTMANN, 1989, p. 325)

Por otra parte, la cantiga 121 vincula explícitamente el rezo del avemaría con las guirnaldas de flores, en una asociación similar a la de la leyenda del surgimiento del rosario franciscano. Particularmente importante, en cuanto a la específica mención del subgénero lírico de los gozos, es la cantiga 6, que relata el milagro del niño que cantaba con 
frecuencia Gaude Virgo Maria, para deleite de todos salvo de un judío que, en un rapto de furia, termina asesinándolo con un hacha. ${ }^{16}$ La Virgen resucita al niño, que ha sido enterrado en una fosa, como si lo estuviera despertando de un profundo sueño, y lo exhorta a cantar nuevamente con esmero.

Otra cantiga, la 71, narra cómo una monja, empeñada en alabar a la Virgen, "un gran livr'enteiro / rezava cada dia" (vv. 12-13), además de practicar la devoción de los mil avemarías a diario. Pero "rezava correndo" (v. 21), y es esta prisa lo que la Virgen misma viene a corregir, pidiendo a la monja, en una aparición nocturna, que rece sólo una tercera parte de sus oraciones y que, sobre todo en la salutación angélica, lo haga "assessegada- /mente e non te coites" (vv.47-48), ya que, según ella misma dice,

quando ouço $\mathrm{u}$ fala como Deus foi comigo, tan gran prazer ey ende, amiga, que che digo que enton me semella que Deus Padr' e Amigo e Fill' en nosso corpo outra vez ben tẽemos"

(vv. 50-53; METTMANN, 1986, p. 237)

${ }^{16}$ En la cantiga 6, además, parece verificarse la misma convergencia entre texto y música (teniendo en cuenta las fuentes litúrgicas) que se observa en otras cantigas, según explica Manuel P. Ferreira: "We know of at least one antiphon starting "Gaude Virgo Maria", but since "Maria" was needed for the rhyme, the song referred to could also read "Gaude Maria Virgo", a wording common to several liturgical pieces. Since the quotation appears in the middle of a melodic phrase, it is not surprising that its music fails to quote any of the melodies associated with "Gaude Maria Virgo" or "Gaude Virgo Maria". These words are nevertheless sung in the Cantiga to the notes de-f-e-c-d-defe-c, which correspond to the incipit of the Marian responsory "Quae est ista quae processit" in its AquitanianHispanic version. Although it is unlikely that a direct quotation was intended here, I am sure that the music rang a familiar bell to a few people in the audience" (FERREIRA, 1999-2000, p. 4). 
Así, pues, en los relatos de milagros marianos y especialmente en las Cantigas de Santa María, la proclamación de los gozos marianos, en estrecha relación con la performance del canto y de la plegaria iterativa, se reviste de la primigenia dimensión del gozo anunciado por el ángel a la Virgen, al que he aludido al inicio de este trabajo. Ella premia, tanto en esta vida como en la futura, a quien canta sus alabanzas y sus gaudia, los cuales hacen memoria de aquella primera salutación angélica, momento histórico que se reactualiza en el presente de la plegaria recitada o cantada, reviviendo así, según ella misma confiesa, el gozo inefable experimentado entonces.

\section{Bibliografía}

ALVAR, Carlos. Poesía de Trovadores, Trouvères y Minnesinger. Madrid: Alianza, 1999.

BEDA EL VENERABLE (Bedae Venerabilis). Hymnus XI. In Natali sanctae Dei Genitricis (Hymni Tredecim). Jacques-Paul Migne. Patrologia Latina. vol. 94, col. 61B, París, 1844-1865.

BLECUA, Alberto (Ed.). JUAN RUIZ, ARCIPRESTE DE HITA. Libro de buen amor. Madrid: Cátedra, 1998.

BLUME, Clemens y Guido M. DREVES (Eds.). Analecta Hymnica Medii Ævi [AHMÆ]. 55 vols. (más índices), Leipzig: Reisland, 18861922 [reimpresión: Frankfurt am Main, 1961; 1978 (índices)].

BURROW, J. A. (Ed.). Sir Gawain and the Green Knight, London: Penguin Classics, 1972.

CARRERA DE LA RED, Avelina y Fátima CARRERA DE LA RED (eds.). Miracula Beate Marie Virginis (Ms. Thott 128 de Copenhague): una fuente paralela a los "Milagros de Nuestra Señora» de Berceo. Colección Centro de Estudios Gonzalo de Berceo, 19, Logroño: Instituto de Estudios Riojanos, 2000. 
CRANE, Thomas Frederick (Ed.). Liber de Miraculis Sanctae Dei Genitricis Mariae. Published at Vienna in 1731 by Bernard Pez, O.S.B. Cornell University Studies in Romance Language and Literature 1, Ithaca-London-Oxford: Cornell University, 1925.

DISALVO, Santiago. El planctus de la Virgen en la Península Ibérica, desde el Quis dabit hasta las Cantigas de Santa María. "El Hispanismo ante el Bicentenario": Actas del IX Congreso de la Asociación Argentina de Hispanistas, M. Mercedes Rodríguez Temperley et al. (Eds.), La Plata: Asociación Argentina de Hipanistas - Universidad Nacional de La Plata, 2012. http:/ /ixcah.fahce.unlp.edu.ar/actas/disalvo-santiago

DONOVAN, Stephen. Franciscan Crown. The Catholic Encyclopedia. New York: Robert Appleton Company, 1908. http:// www.newadvent.org/cathen/04540a.htm

FABER, Frederick William. Todo por Jesús, tomo I, Madrid: Librería de Don Miguel Olamendi, 1866. [ed. original 1853, All for Jesus, or The Easy Ways of Divine Love]

FERREIRA, Manuel Pedro. The influence of chant on the Cantigas de Santa Maria. Bulletin of the Cantigueiros de Santa Maria, n. 11-12, p. 29-40, 1999-2000. [1999, Publicações CESEM, Universidade Nova de Lisboa. http://www.fcsh.unl.pt/29_10_02/revistas / mpf_chant99.htm]

GERLI, Michael (Ed.). GONZALO DE BERCEO. Milagros de Nuestra Señora. Madrid: Cátedra, 2003 [1 ${ }^{a}$ ed. 1985].

GOLLANCZ, Israel. Cynewulf's Christ. An Eighth Century English Epic. London: David Nutt in the Strand, 1892.

GÓMEZ MORENO, Ángel. Nuevas reliquias de la cuaderna vía. Revista de Literatura Medieval, n. 2, p. 9-34, 1990.

GÓMEZ MORENO, Ángel. Los Gozos de la Virgen en el ms. 9/5809 de la Real Academia de la Historia. Studia in honorem prof. M. de Riquer, Barcelona: Quaderns Crema, p. 233-245, 1991.

GÓMEZ MORENO, Ángel y Maximilian P. A. M. KERKHOF (Eds.). Íñigo López de Mendoza, Marqués de Santillana. Obras completas. Barcelona: Planeta, 1988. 
GÓMEZ MUNTANÉ, Carmen. El Llibre Vermell de Montserrat: cantos y danzas s. XIV. Barcelona: Libros de la Frontera, 1990.

GONZÁLEZ-BLANCO GARCÍA, Elena. Las raíces del «mester de clerecía». Revista de Filología Española, LXXXVIII. 1º , p. 195-207, 2008.

HESBERT, René-Jean (ed.). Corpus Antiphonalium Officii. 6 vols., Roma: Herder, 1963-1979.

KOENIG, Frédéric (ed.). GAUTIER DE COINCI. Miracles de Nostre Dame. vols. I (2ª ed.)-IV, Genève: Droz, 1966, 1961, 1970.

LÁZARO POLO, Francisco. A. Rasgos estilísticos de los Gozos de la Virgen de las Cuevas, Patrona de Caminreal. Xiloca, n. 3, p. 123-138, 1989.

METTMANN, Walter (ed.). ALFONSO X, EL SABIO. Cantigas de Santa María. T. I-III, Madrid, Castalia, 1986, 1988, 1989.

MORREALE, Margherita. Los "Gozos" de la Virgen en el Libro de Juan Ruiz (I). Revista de Filología Española, LXIII (3-4), p. 223-290, jul.-dic. 1983.

MORREALE, Margherita. Los "Gozos" de la Virgen en el Libro de Juan Ruiz (II). Revista de Filología Española, LXIV (1-2), p. 1-60, ene.jun. 1984.

MORSEL, Joseph. La aristocracia medieval. La dominación social en Occidente (siglos $V$-XV), Publicacions de la Universitat de València, 2008.

NORTHCOTE Toller, T. An Anglo-Saxon dictionary, based on the manuscript collections of the late Joseph Bosworth. Supplement. Oxford: Clarendon, 1921. [vol. principal: Joseph Bosworth \& T. Northcote Toller,1898]

PELTOMAA, Leena Mari. The Image of the Virgin Mary in the Akathistos hymn. The Medieval Mediterranean 35, Leiden: Brill, 2001.

ROMERO FRÍAS, Marina. Gòsos, gòccius... goigs. A próposito de una edición del Index libri vitae de Giovanni Delogu Ibba. Espéculo. Revista de estudios literarios, n. 33, 2006. http:/ / www.ucm.es/info/ especulo/numero33/gdelogu.html 
SÁNCHEZ UNGRÍA, María José. Folklore popular de La Litera: los Gozos. Comarca de La Litera, Arturo Palomares Puertas y Juan Rovira Marsal (coord.), Colección Territorios, 29, Diputación General de Aragón, p. 257-262, 2008.

SNOW, Joseph. The Central Rôle of the Troubadour Persona of Alfonso X in the Cantigas de Santa María. Bulletin of Hispanic Studies, n. 56, p. 305-316, 1979.

VICENTE DE BEAUVAIS (Vincentius Bellovacensis).Speculum historiale [Bibliotheca mundi Vincentii Burgundi ex ordine Praedicatorum vener. Episcopi Bellovacensis. Speculum quadruplex, naturale, doctrinale, morale, historiale..., t. IV], Theologorum Benedictinorum Collegii Vedastini (Academia Duacensi), Duaci (Douai): Balthazar Bellere, 1624.

WEBER, Sarah Appleton. Theology and Poetry in the Middle English Lyric. A Study of Sacred History and Aesthetic Form, Columbus: Ohio State University Press, 1969.

\section{Resumen}

El subgénero lírico de los gozos fue cultivado con mucha frecuencia durante la Edad Media como himnos litúrgicos $\mathrm{y}$, más tarde, como poemas de tipo popularizante muchas veces $y$, otras, en la poesía cortesana, hasta entrar en la modernidad con diversas formas folklóricas. Desde antes del año 1000 la cristiandad había evocado y celebrado el gozo de la Madre de Dios en variadas formas poéticas. Este gozo era cantado en el Akáthistos griego y mencionado en la poesía anglosajona de Cynewulf a María. A partir del siglo XI ya encontramos conformado un subgénero lírico particular, los gaudia de la Virgen ("Gaude, Virgo Mater Christi"). Con diferentes reformulaciones, hasta entrar en los siglos XIV y XV con la pluma de Juan Ruiz, Arcipreste de Hita, y del Marqués de Santillana, entre otros, el subgénero él se manifiesta asimismo en España. En una 
evolución textual en la que se intervienen también la práctica de la "corona franciscana" y el culto mariano de los servitas, los gaudia estarán así presentes en la poesía latina y vernácula (inglesa, francesa, catalana, castellana), alternando el número de los "gozos" principalmente entre 5 y 12. En las Cantigas de Santa María, los gozos son siete y aparecen ya en el inicio del cancionero, en la cantiga 1. Finalmente, aunque sean considerados poesía lírica, entrarán también en las narraciones de milagros marianos, en las que los protagonistas cantan los gozos de la Virgen (en las colecciones de milagros latinos y, más tarde, en los Miracles de Nostre Dame de Gautier de Coinci, en las Cantigas de Santa María de Alfonso X y en los Milagros de Nuestra Señora de Gonzalo de Berceo.).

\section{Resumo}

O subgênero lírico dos "gozos" foi cultivado muito freqüentemente durante a Idade Média como hinos litúrgicos e, mais tarde, como poemas de tipo popularizante muitas vezes e, outras vezes, na poesia cortesã, até entrar na modernidade sob diversas formas folclóricas. Desde antes do ano 1000 a cristandade tinha evocado e comemorado o gozo da Mãe de Deus em variadas formas poéticas. Este gozo era cantado no Akáthistos grego e mencionado na poesia anglo-saxônica de Cynewulf a Maria. A partir do século XI já é possível encontrarmos conformado um subgênero lírico particular, os gaudia da Virgem ("Gaude, Virgo Mater Christi"). Com reformulações diferentes, até entrar nos séculos XIV e XV sob a pluma de Juan Ruiz, Arcipreste de Hita, e do Marquês de Santillana, entre outros, o subgênero manifesta-se igualmente na Espanha. Sob uma evolução textual na qual intervêm a prática da "coroa franciscana" e o culto mariano dos servitas, os gaudia estarão presentes 
assim na poesia latina e vernácula (inglês, francês, catalão, castelhano), alternando o número dos "gozos" principalmente entre 5 e 12. Nas Cantigas de Santa Maria, os gozos são sete e aparecem já no início do cancioneiro, na cantiga 1. Finalmente, embora sejam considerados poesia lírica, ingressarão também nas narrações dos milagres marianos, em que os protagonistas cantam os gozos da Virgem (nas coleções de milagres latinos e, mais tarde, nos Miracles de Nostre Dame de Gautier de Coinci, nas Cantigas de Santa Maria de Alfonso X e nos Milagros de Nuestra Señora de Gonzalo de Berceo). 